\title{
到達圧力付近に拈ける真空排気系の 動的バランスの測定*
}

寺田 啓子**. 岡野 達雄 ${ }^{* *}$. 过 泰**

（昭和63年 2 月 5 日 受理）

Measurement of Gas Balance in Vacuum

Systems in the Ultimate Pressure Region

Keiko TERADA**, Tatsuo OKANO** and Yutaka TUZI**

(Institute of Industrial Science, University of Tokyo, Minato-ku, Tokyo, Japan)

(Received February 5, 1988)

\section{1. はじめに}

真空装置の到達圧力は, 真空容器内で放出される全気 体放出速度とポンプの排気速度とのバランスできまる. 超高真空装置の到達圧力付近では, 真空容器内壁 (ここ では, 容器内のすべての表面を含むものとする）からの 全気体放出速度に対して，ポンプ自身から放出される気 体の全放出速度が無視できなくなり，ポンプはその気体 も合わせて排気しているため, ポンプ外からの気体に対 する実効的な排気速度 (measured pumping speed ${ }^{1)}$ ) が 低下する. しかし, 到達圧力付近では排気速度の測定 が, 困難なため, 真空容器内壁やポンプからの気体放出 速度を求めることも困難となり, 到達圧力を決める要因 を比較検討することも難しい。

筆者らは, 既知のコンダクタンスを基準にしてポンプ の排気速度を求めるコンダクタンス変調法 ${ }^{2}$ に改良を加 え, それが気体流量の少ない超高真空領域におけるポン プの排気速度測定に有効であることを示した ${ }^{3)}$. 本研究 では, この方法によって, 超高真空装置が到達圧力に達 した状態におけるポンプの実効的な排気速度を測定し， その結果を用いて真空容器内壁からの全気体放出速度を 求め, それらの到達圧力への寄与を検討することを試み た。

\footnotetext{
* 昭和62年11月 13 日 第28回真空に関する連合講演会で講演 (13Ap-2)
}

** 東京大学生産技術研究所 東京都港区六本木7-22-1

\section{2. 実験装置と測定原理}

測定に使用した真空系の模式図を Fig. 1 に示す．同 図の中の A と B は, 同一真空系でオリフィス系をそれ ぞれAまたはBの状態にした場合を示している．真空 容器は450 mm $\phi \times 400 \mathrm{~mm}$ のステンレス鋼製で, コンダ クタンスを真空装置の外から変えることができるオリフ ィス系を介して, 同じ直径のスパッター・イオン・ポン プ（SIP）とチタン・ゲッター・ポンプ（TGP，液体窒

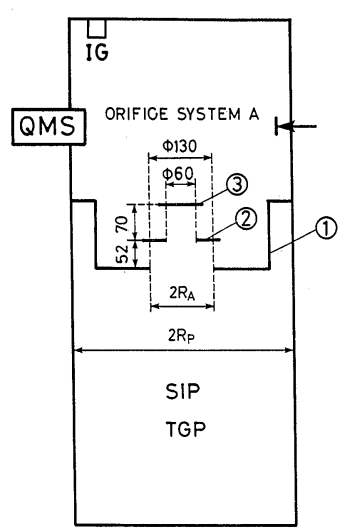

A

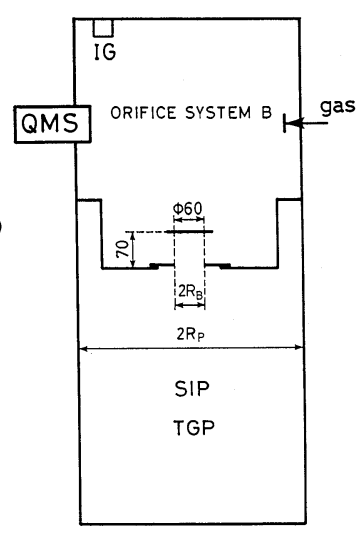

B
Fig. 1 Schematic diagram of two state of conductance modulation:

A: High-conductance position.

B: Low-conductance Position. 


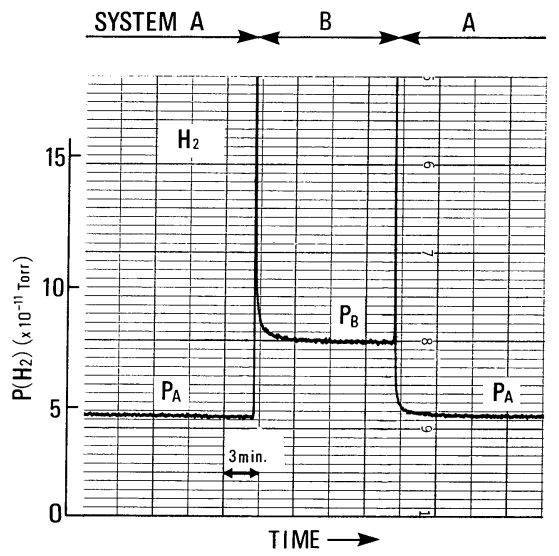

Fig. 2 Ghange of the partial pressure of hydrogen in vacuum chamber correspond to the conversion of orifice system in the ultimate pressure region.

素冷却）により排気されている，真空容器には，全圧を 測定するためのベアード・アルパート真空計 (IG) と 分圧を測定するための四極子型分圧真空計（QMS）が 取り付けてあり, $250^{\circ} \mathrm{C}, 8$ 時間の加熱脱ガス後の到達圧 力は $3 \times 10^{-11}$ Torrである.

コンダクタンス変調法では, 真空容器に外部から導入 する気体の流量を一定に保ち，可動オリフィスを A 状 態から B（または B から A）に変え，各オリフィス采 に対する容器内の圧力の比を求めることにより，ポンプ の排気速度を得ることができる. 本研究では, 気体流量 の絶対值が不要であるという特長を生かし, 容器内壁か らの気体放出速度が測定時間内で一定であると仮定し て，それより圧力の決まる到達圧力状態でのポンプの実 効的な排気速度の測定を行い, また, 真空容器内の圧力 の測定値から容器内壁からの全気体放出速度を求めた. 測定は，超高真空系の到達圧力付近で最も主要な残留気 体である水素（QMS で測定）について行なった.

到達圧力付近でオリフィス系を A から B B B から A に 変えると, 容器内の水素分圧はFig. 2上万に, それぞ れ $P_{\mathrm{A}}$ から $P_{\mathrm{B}}, P_{\mathrm{B}}$ から $P_{\mathrm{A}}$ に変わる。このよらな測定に よってポンプ固有の排気速度 (intrinsic pumping speed ${ }^{1}$ ) を求めるコンダクタンス変調法については，すでに報告 してあるので, ここでは到達圧力状態における測定につ いて簡単に述べる.

Fig. 3 は, オリフィス系が A の場合を例にして, 真 空系内の全気体放出速度と排気速度の関係を模式的に示 したものである.ポンプが本来持っている固有の排気速 度を $S_{\mathrm{P}}$, 外部から真空容器に導入する気体流量を $Q$, 真空容器内壁からの全気体放出速度を $Q_{\mathrm{w}}$, ポンプ自身

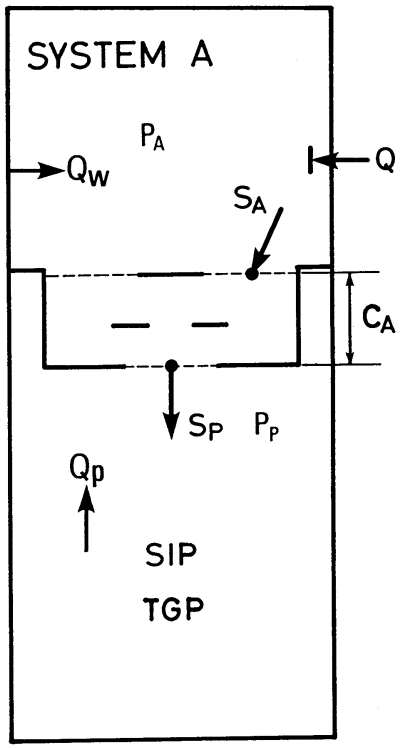

Fig. 3 Illastration of the quantities appeard in equations.

からの全気体放出速度を $Q_{\mathrm{P}}$ とすると, ポンプ入口の圧 力 $P_{\mathrm{P}}$ は

$$
P_{\mathrm{P}}=\frac{Q+Q_{\mathrm{W}}+Q_{\mathrm{P}}}{S_{\mathrm{P}}}=\frac{Q+Q_{\mathrm{W}}}{S_{\mathrm{P}}}+P_{\mathrm{P} 0}
$$

となる． $P_{\mathrm{P} 0}$ はポンプ自身から放出する気体をポンプが 排気することによる圧力成分で，真空容器側にポンプが ないとすれば, 分子流条件下では $P_{\mathrm{P} 0}$ は容器全域で同じ になる。 $Q_{\mathrm{P}}, P_{\mathrm{P} 0}$ は実測不可能な量なので， $Q_{\mathrm{P}}$ の寄与を 含むポンプの実効的な排気速度 $S$ を導入すれぱ

$$
P_{\mathrm{P}}=\frac{Q+Q_{\mathrm{W}}}{S}
$$

となる、したがって(1)，(2)式から，Sと $S_{\mathrm{P}}$ との関倸 は

$$
S=\frac{Q+Q_{\mathrm{W}}}{Q+Q_{\mathrm{W}}+Q_{\mathrm{P}}} S_{\mathrm{P}}
$$

となる.

真空容器に対する排気速度 $S_{\mathrm{A}}$ はオリフィス系のコン ダクタンス $C_{\mathrm{A}}$ と $S$ との合成として，(4)式で表わすこ とができる，Bについても同様に（5)式のようになる.

$$
\begin{aligned}
& \frac{1}{S_{\mathrm{A}}}=\frac{1}{C_{\mathrm{A}}}+\frac{1}{S}-\frac{1}{\frac{\bar{v}}{4} \pi R_{\mathrm{P} 2}} \\
& \frac{1}{S_{\mathrm{B}}}=\frac{1}{C_{\mathrm{B}}}+\frac{1}{S}-\frac{1}{\frac{\bar{v}}{4} \pi R_{\mathrm{P} 2}}
\end{aligned}
$$

ここで, $C_{\mathrm{A}}$ と $C_{\mathrm{B}}$ はモンテカルロ法によって得た值を使 


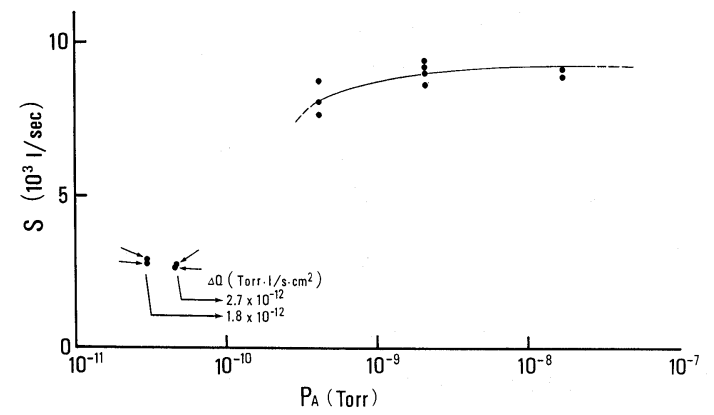

Fig. 4 Pressure dependence of the measured pumping speeds of pump consisted of SIP and TGP for hydrogen gas.

用しており，室温の水素については $C_{\mathrm{A}}=4295 \mathrm{l} / \mathrm{s}$, $C_{\mathrm{B}}=1194 \mathrm{l} / \mathrm{s}$ である. $R_{\mathrm{P}}$ はポンプの半径, $\bar{v}$ は室温にお ける気体の平均速度である. 外部からの気体導入のない, $Q=0, Q_{\mathrm{W}}=$ const. の条件となった到達圧力状態では, $P_{\mathrm{A}}, P_{\mathrm{B}}$ と $S_{\mathrm{A}}, S_{\mathrm{B}}$ の関係は次式のように表わしてよいであ ろう.

$$
Q_{\mathrm{W}}=P_{\mathrm{A}} S_{\mathrm{A}}=P_{\mathrm{B}} S_{\mathrm{B}}=P_{\mathrm{P}} S
$$

すなわち,

$$
\frac{S_{\mathrm{A}}}{S_{\mathrm{B}}}=\frac{P_{\mathrm{B}}}{P_{\mathrm{A}}}
$$

となる。したがって, 測定値 $P_{\mathrm{A}}, P_{\mathrm{B}}$ と (4), (5), (7) 式 とから $S, S_{\mathrm{A}}, S_{\mathrm{B}}$ が求まる。さらに, $P_{\mathrm{A}}, P_{\mathrm{B}}$ の值と $S_{\mathrm{A}}$, $S_{\mathrm{B}}$ の值を用いれば， $Q_{\mathrm{W}}$ を求めることがでさる。 また, $Q_{\mathrm{W}}$ と $Q_{\mathrm{P}}$ に起因する真空容器内の圧力を, バックグラ ウンドとして(6)式の $P_{\mathrm{A}}, P_{\mathrm{B}}$ から差し引くと， $S_{\mathrm{P}}$ を求め ることができる3).

\section{3. 実験結果とまとめ}

$Q_{\mathrm{W}}$ が排気速度測定時間内で変化しないものと仮定す ると， 82 で示した方法を用いて，SIPと TGP の複合排 気系の到達圧力状態に打ける水素に対する $S$ として,

Fig. 4 の矢印の 4 点が得られた. 図の横軸は,オリフィ ス系 $\mathrm{A}$ を用いたときの容器内の圧力 $P_{\mathrm{A}}$ である。 $P_{\mathrm{A}}$ が $10^{-10} \sim 10^{-8}$ Torr の圧力領域に打ける測定值（実線の上 下に分布）は，外部から容器に水素を導入して求めた $S$ の值である.この值は， $\bigotimes \gg Q_{\mathrm{W}}+Q_{\mathrm{P}}$ において $S_{\mathrm{P}}$ に近づ $<$.

矢印で示した測定值は，外部から水素を流し込んで測 定した值の約 $1 / 3$ になっている。このことは, 到達圧力 付近では，ポンプ自身から放出する気体をポンプが排気 することの影響が大きく，ポンプ外からの気体に対する 排気速度が著しく低下していることを示している，矢印 の点に対する. $S_{\mathrm{A}}, S_{\mathrm{B}}$ と $P_{\mathrm{A}}, P_{\mathrm{B}}$ の值を使って, 容器内壁

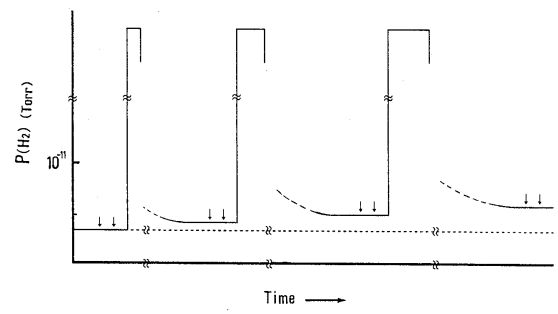

Fig. 5 Illustration of the variation of pressure during the measurement of pumping speed as a function of total amount of gas pumpd.

The rectangular pressure pulse correspond to the gas inlet. The measurement is made at the quiescent region long after the gas inlet.

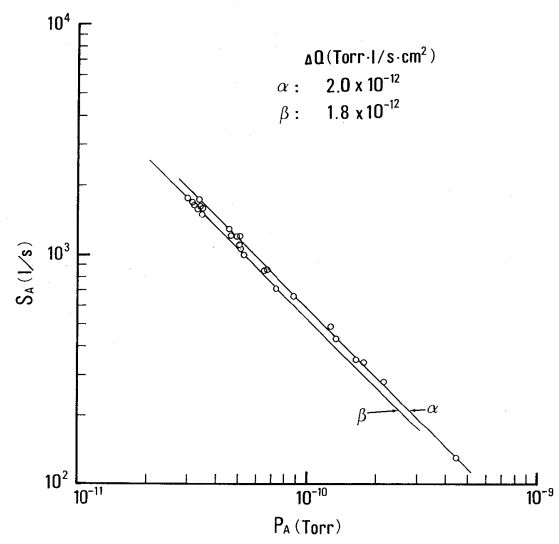

Fig. 6 Relation between the ultimate partial pressure and the pumping speed in the vacuum chamber for hydrogen.

からの単位面積あたりの気体放出速度 $\Delta Q_{\mathrm{W}}$ を求めてみ ると, $2.7 \times 10^{-12}$ Torr $\cdot 1 / \mathrm{s} \cdot \mathrm{cm}^{2}, 1.8 \times 10^{-12}$ Torr $\cdot 1 / \mathrm{s} \cdot \mathrm{cm}^{2}$ となり，いずれも，十分脱ガスされたステンレス鋼から の単位面積あたりの気体放出速度と同程度の値を示し た4).

気体ため込み式真空ポンプで排気している真空系に気 体を大量に流した後には, 到達圧力が高くなるという現 象が観測される。この原因としては，Sの低下と， $Q_{\mathrm{W}}$ の増加が考えられるので, コンダクタンス変調法を使っ て検討した。

Fig. 5 は, 横軸を時間, 縦軸を真空容器内の水素の分 圧として，実験の経過を模式的に示したものである。ま ず，容器を十分脱ガスし，ポンプも十分活性化した状態 で到達圧力状態に打ける $S$ を測定する. 次に，水素を適 当な流量で，ある時間だけ導入し，導入を止めた後，圧 力が低下して安定になり到達圧力に達したと思われると 
ころで $S$ を測定する (矢印)。この操作を繰返し, 総気 体導入量が 1.3 Torr $l$ になるまで測定を行なった.

このようにして得られた結果を, 横軸を測定時の到達 圧力 $P_{\mathrm{A}}$, 縦軸を $S_{\mathrm{A}}$ としてまとめると Fig. 6 が得られ る. 水素を排気したことによる到達圧力の上昇は， $S_{\mathrm{A}}$ の減少に注比例していることが分かる. 図中の直線 $\alpha, \beta$ は $\Delta Q_{\mathrm{W}}$ 一定の線で, $\alpha$ が $\Delta Q_{\mathrm{W}}=2.0 \times 10^{-12}$ Torr $\cdot l / \mathrm{s} \cdot \mathrm{cm}^{2}, \beta$ が $\Delta Q_{W}=1.8 \times 10^{-12} \mathrm{Torr} \cdot l / \mathrm{s} \cdot \mathrm{cm}^{2}$ である. 測定点は，ほぼこれら 2 本の線の間收まっている。こ のことは, この一連の測定の間, 真空容器内壁からの単 位面積あたりの気体放出速度が，上記の値の間でしか変 化していないこを示している，すなわち，水素を大量に 排気した後に到達圧力が上昇する原因は, 主に $Q_{\mathrm{P}}$ の増 加によって，Sが低下することによるものであると考光 ることができる。しかし，Fig. 6 では， $P_{\mathrm{A}}$ が上昇する に伴い測定点が $\beta$ 線上から $\alpha$ 線上に移動している傾向 が見られるので, 総気体導入量が増加したための到達圧 力の上昇には，わずかではあるが $Q_{\mathrm{W}}$ の増加も寄与して いるものと思われる. 他の気体の場合, 特に真空容器内 壁と相互作用の大きい気体の場合には異なる結果が得ら
れることが予想される。

以上の結果から，コンダクタンス変調法によれば, 到 達圧力状態に拈ける $S, \Delta Q_{\mathrm{W}}$ などを測定し得ることが明 らかとなった。 この方法では, 真空容器に外部から気体 を一定流量で導入すれば $S_{\mathrm{P}}$ も測定し得るので3)， $S_{\mathrm{P}}, S$, $Q_{\mathrm{W}}$ の值を(7)式に代入することによって， $Q_{\mathrm{P}}$ も求める ことができる.したがって, 超高真空装置の到達圧力付 近における, 真空容器内壁からの全気体放出速度, ポン プ自身の全気体放出速度，ポンプの固有の排気速度の間 のバランスによって決まる真空系の特性の測定と解析 に，きわめて有力な方法であると思われる。

\section{〔文献〕}

1) Committee on Standards, American Vacuum Society: Glossary of Terms Used in Vacuum Technology (Pergamon, 1958)

2) C.W. Oatley: Brit. J. Appl. Phys. 5 (1954) 358.

3）寺田啓子, 辻泰, 岡野達雄 : 真空 31 (1988) 259.

4）小宮宗治：真空技術，林主税編（共立出版株式会社 1985） 9.2 節. 